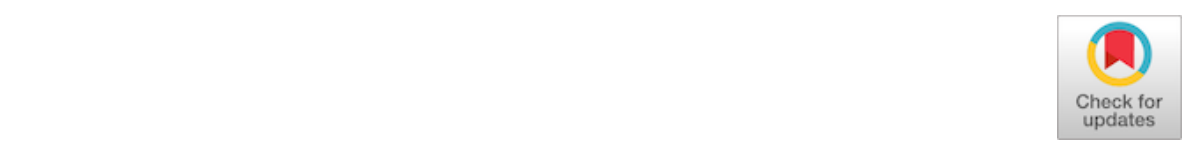

\title{
José Félix Patiño Restrepo
}

\author{
José Ricardo Navarro-Vargas \\ Decano de medicina, Universidad Nacional de Colombia.
}

El pasado 26 de febrero falleció el profesor José Félix Patiño Restrepo (San Cristóbal, Venezuela I927 - Bogotá, D.C., Colombia 2020), dejando un enorme y precioso legado por su férrea forma de abordar la educación, el profesionalismo, la ética y la búsqueda de los más eximios valores del individuo frente a su responsabilidad social.

El Profesor Patiño Restrepo era un personaje singular, que le encantaba escuchar a las personas y compartir con ellas su amor por la vida, por la salud, por la profesión médica, por la educación. Consideraba a Abraham Flexner el gran reformista y transformador de la educación médica, destacaba que este educador americano desde comienzo del siglo XX se refería a la educación médica como un sistema pedagógico, y a la facultad de medicina como una comunidad moral y, siendo una división universitaria, también debía de ser una corporación de servicio público.

Siempre se preocupó por poner a Colombia en la modernidad y criticar con argumentos ciertos y convincentes La Ley IOo de I993, por cuanto favoreció el negocio de la salud, la explotación de los profesionales de la salud y el papel denigrante, como agentes remitidores, que tuvieron que asumir los médicos generales. De su libro Pensar la medicina es el siguiente planteamiento: " $\mathrm{La}$ organización social moderna y las nuevas modalidades de prestación de servicios de salud introducen cambios profundos en el ejercicio de la medicina y crean nuevos problemas como la rup-

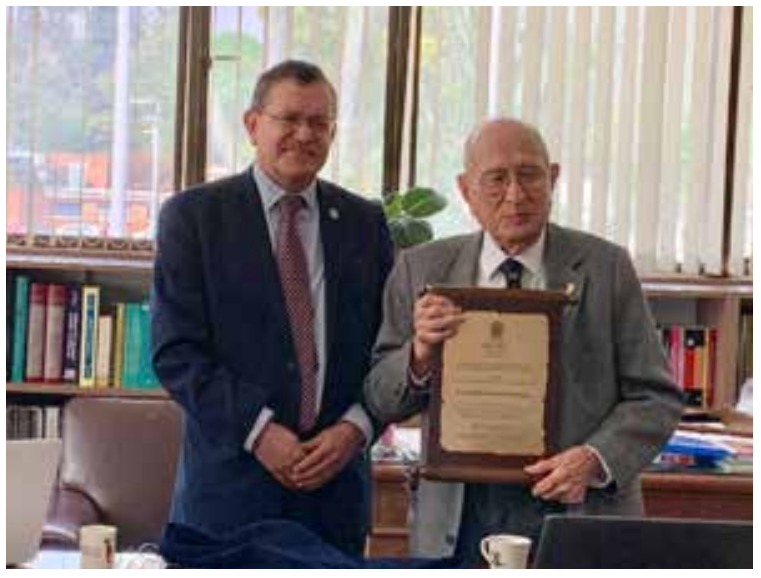

tura de la relación médico-paciente, el deterioro de la imagen pública del médico, el surgimiento del paciente como consumidor y las complejas implicaciones de la medicina tecnológica".

De todas las actividades, siempre prolíficas y de avanzada, que le tocó asumir en su vasta trayectoria profesional, se enorgullecía y se honraba de haber asumido la rectoría de la Universidad Nacional de Colombia en la década del 6o, donde "no querían a los rectores". Como precedente, ocho rectores habían corrido con la suerte de no terminar su período, pero él se ganó el aprecio, respaldo y agradecimiento de la comunidad académica porque supo escucharla y ponerla del lado del progreso que requería la ciudad universitaria, y allí pudo implementar la mayor reforma universitaria del país, en el año I965, "La reforma Patiño".

Fecha de recibido: 08/03/2020 - Fecha de aceptación: 23/07/2020

Correspondencia: José Ricardo Navarro-Vargas. Correo electrónico: jrnavarrov@unal.edu.co

Citar como: Navarro-Vargas JR. José Félix Patiño Restrepo. Rev Colomb Cir. 2021;36:18-9

Este es un artículo de acceso abierto bajo una Licencia Creative Commons - BY-NC-ND https://creativecommons.org/licenses/by-nc-nd/4.0/deed.es 
En cada cargo que asumió dejaba una valiosa estela de construcción y un derrotero de aprendizaje y enseñanza. A los 35 años de edad (en 1962) fue ministro de salud bajo la presidencia de Guillermo León Valencia; antes había sido jefe de cirugía del Hospital La Samaritana, y posteriormente fue fundador de la Fundación Santa Fe de Bogotá, fundador de la Facultad de Medicina de la Universidad de los Andes, presidente de la Academia Nacional de Medicina $\mathrm{y}$, en sus últimos 2 años de vida, fue miembro del Consejo Superior de la Universidad Nacional de Colombia, universidad que amó con toda su alma, hasta desprenderse incondicionalmente de su valiosa biblioteca personal, que entre otros memorables libros cuenta con una colección de la obra de nuestro premio nobel de literatura, Gabriel García Márquez.

Siempre quedará en nuestra memoria su ejemplo de gran hombre, culto, justo, honorable, transparente, que luchó por ver un sistema de salud donde no sólo haya el goce del derecho a la salud y el claro privilegio para el cuidado integral del ciudadano, sino también un justo reconocimiento para el trabajo digno y la autonomía del profesional de la medicina, pues fue uno de los artífices de la ley estatutaria de salud, ley I75I de 2015.

Gracias doctor José Félix Patiño Restrepo por haberme brindado su amistad y habernos abierto su alma de hombre bueno. 